\title{
Chromium Speciation Analysis by Solid-Phase Extraction on Titanium Dioxide Nanotubes and Inductively Coupled Plasma Mass Spectrometry
}

\author{
Shizhong Chen*a, Shengping $\mathrm{Zhu}^{\mathrm{b}}$, and Dengbo $\mathrm{Lu}^{\mathrm{a}}$ \\ ${ }^{a}$ College of Chemical and Environmental Engineering, Wuhan Polytechnic University, \\ Wuhan 430023, P.R. China \\ ${ }^{b}$ Department of Chemistry, Yunyang Teacher's College, Danjiangkou 442700, Hubei, P.R. China
}

\section{INTRODUCTION}

In recent years, chemical speciation of an element has been drawing growing attention in the fields of environmental, toxicological, nutritional, medical, and analytical science (1). Chromium speciation is of great interest because its toxicity depends upon its oxidation state. Cr(III) is considered to be essential to mammals for the maintenance of the glucose, protein and lipid metabolism $(2,3)$. On the other hand, $\mathrm{Cr}(\mathrm{VI})$ is reported to be toxic for biological systems even at relatively low levels (4). Therefore, it is of increasing importance to monitor the concentration of individual chromium species.

Up to now, the direct determination of chromium species has not been possible by instrumental methods, including inductively coupled plasma atomic emission spectrometry (ICP-AES), inductively coupled plasma mass spectrometry (ICP-MS), and atomic absorption spectrometry (AAS). To perform speciation, a chemical separation and pre-concentration step is often required prior to analysis. A variety of methods, including solvent extraction, coprecipitation, ion exchange, solid-phase extraction, chelating resin adsorption, chromatography, and catalytic cathodic stripping voltammetry, have been developed for $\mathrm{Cr}$ speciation (5-12). Among these procedures, solidphase extraction has attracted considerable practical interest in

*Corresponding author.

E-mail: chenshizhong62@163.com

\section{ABSTRACT}

A novel method was developed for the speciation of inorganic chromium by titanium dioxide nanotubes as a solid phase extractant and inductively coupled plasma mass spectrometry (ICP-MS). In order to achieve the quantitative separation of Cr(III) and Cr(VI), experiments were performed to optimize conditions such as $\mathrm{pH}$, sample flow rate, sample volume, and concentration of the eluent. During the separation steps, $\mathrm{Cr}$ (III) was selectively sorbed on the column packed with $\mathrm{TiO}_{2}$ nanotubes in the $\mathrm{pH}$ range of 5.0-8.0, while Cr(VI) was found to remain in solution. The retained $\mathrm{Cr}$ (III) was subsequently eluted with $2.0 \mathrm{~mL}$ of $1.5 \mathrm{~mol} \mathrm{~L}^{-1}$ nitric acid.

The detection limit of $\mathrm{Cr}$ (III) for this method was $0.023 \mathrm{ng}$ $\mathrm{mL}^{-1}$, and the relative standard deviation (RSD) for $\mathrm{Cr}(\mathrm{III})$ was $3.8 \%\left(n=9, c=0.5 \mathrm{ng} \mathrm{mL}^{-1}\right)$. The linear range of the calibration curve spanned three orders of magnitude. The proposed method was applied to the determination of $\mathrm{Cr}$ (III) and $\mathrm{Cr}(\mathrm{VI})$ in water samples with the recovery of $94.2-102 \%$.

comparison to the traditional liquidliquid extraction methods because of its major advantages: (i) simplicity of operation, (ii) high concentration factor, (iii) rapid phase separation, and (iv) ability to combine with different detection techniques (13). It should be noted that the adsorbent material plays a fun- damentally important role in this technique, and the development of a new adsorbent material with high selectivity and sensitivity is forever of interest to analysts. Owing to the small size, large specific surface area, excellent mechanical strength, high chemical stability, and unique electrical properties, nanostructure materials as a new adsorbent for preconcentration and separation of a substance have drawn growing attention in the analytical sciences. Some nanometersize substances, such as carbon nanotubes, carbon nanofibers, nanometer-size titanium dioxide, nanometer-size zirconium oxide, FeC nanoparticles, and nanometersize silicon dioxide have been successfully used as solid-phase extractants for preconcentration/ separation of metal and nonmetal ions (14-19), as well as adsorption of organic compounds (20).

$\mathrm{TiO}_{2}$ nanotubes have been used for the photodegradation as the photocatalyst. However, they should have much higher adsorption capacity than that of $\mathrm{TiO}_{2}$ nanoparticles because they have been shown to have a large surface area, which makes them promising candidates as adsorbers $(21,22)$. To the best of our knowledge, however, studies on the application of $\mathrm{TiO}_{2}$ nanotubes to the analysis of elemental speciation have received little attention. The main aim of this work was to develop $\mathrm{TiO}_{2}$ nanotubes as a new adsorbent for the simultaneous separation and determination of inorganic chromium speciation by ICP-MS. The adsorption characteristics of $\mathrm{TiO}_{2}$ nanotubes for the analytes were investigated in detail. The proposed 
method was applied to the speciation of inorganic chromium in water samples with satisfactory results.

\section{EXPERIMENTAL}

\section{Instrumentation}

An X-7 ICP-MS system (Thermo Elemental Corporation, USA) was used for the analysis. The optimum operating conditions for the ICP-MS are summarized in Table I.

The $\mathrm{pH}$ values of the solutions were measured with a $\mathrm{pH}$ meter (Thermo Orion Corporation, USA), supplied with a combined electrode. An HL-2 peristaltic pump (Shanghai Qingpu Huxi Instrument Factory, P.R.China), coupled with a self-made polytetrafluoroethylene (PTFE) microcolumn $(20 \mathrm{~mm} \times$ $3.0 \mathrm{~mm}$ i.d.) packed with $\mathrm{TiO}_{2}$ nanotubes, was used for the preconcentration/separation process. A minimum length of PTFE tube with a $0.5 \mathrm{~mm}$ i.d. was used for all connections.

\section{Standard Solutions and Reagents}

The stock standard solution (1.0 $\mathrm{mg} \mathrm{mL}^{-1}$ ) of Cr(III) was obtained from the National Analysis Center of Iron \& Steel (Beijing, P.R. China); $\mathrm{Cr}(\mathrm{VI})$ was prepared by dissolving $\mathrm{K}_{2} \mathrm{Cr}_{2} \mathrm{O}_{7}$ (Tianjin Reagent Factory, Tianjin, P.R. China) in $0.1 \mathrm{~mol} \mathrm{~L}^{-1}$ nitric acid. Working solutions were prepared daily by appropriate dilution of stock solutions. All reagents used were ultrapure or at least of analytical grade. High purity deionized water (18.2 M $\Omega$ ) obtained from Milli-Q $\mathrm{Q}^{\mathrm{TM}}$ A10 system (Millipore Corporation, USA) was used throughout this work.

\section{Sample Preparation}

Water samples were collected from Wuhan (P.R. China) and stored in prewashed polyethylene bottles. Before analysis, the water samples were filtered through a cellulose membrane filter of $0.22 \mu \mathrm{m}$ pore size. The $\mathrm{pH}$ of the samples was adjusted to the desired value with $\mathrm{HNO}_{3}$ and $\mathrm{NH}_{3} \cdot \mathrm{H}_{2} \mathrm{O}$. Then the procedure given above was applied to the samples. The blanks were prepared in the same way as the sample, but omitting the sample.

\section{Column Preparation}

A PTFE microcolumn $(20 \mathrm{~mm} \times$ $3.0 \mathrm{~mm}$ i.d.), plugged with a small portion of glass wool at both ends, was filled with $100 \mathrm{mg}$ of $\mathrm{TiO}_{2}$ nanotubes. Before use, $1.0 \mathrm{~mol} \mathrm{~L}^{-1}$ $\mathrm{HNO}_{3}$ solution and high purity deionized water were passed through the column in order to clean and condition it. Then, the column was conditioned to the desired $\mathrm{pH}$ with $\mathrm{HNO}_{3}$ and $\mathrm{NH}_{3} \cdot \mathrm{H}_{2} \mathrm{O}$.

\section{General Procedure}

An aliquot of aqueous sample solution containing $\mathrm{Cr}$ (III) and $\mathrm{Cr}$ (VI) was prepared, and the $\mathrm{pH}$ was adjusted to the desired $\mathrm{pH}$ with $\mathrm{HNO}_{3}$ and $\mathrm{NH}_{3} \cdot \mathrm{H}_{2} \mathrm{O}$ before use. The obtained solution was passed through the column by using a peristaltic pump at the desired flow rate. Cr(III) was retained on the column, while Cr(VI) was collected in the effluent. Afterwards, the sorbed Cr(III) was eluted with $2.0 \mathrm{~mL}$ of $1.5 \mathrm{~mol} \mathrm{~L}^{-1}$ $\mathrm{HNO}_{3}$. The $\mathrm{Cr}$ concentration was determined in the two fractions by ICP-MS.

\section{RESULTS AND DISCUSSION}

\section{Effect of pH on Adsorption of Cr(III) and Cr(VI)}

In this work, the $\mathrm{pH}$ value plays an essential role with respect to the adsorption of different species of chromium on $\mathrm{TiO}_{2}$ nanotubes since it affects the surface charge of the adsorbent and speciation of the adsorbates. Thus, the effect of the $\mathrm{pH}$ on the retention of $\mathrm{Cr}(\mathrm{III})$ and $\mathrm{Cr}(\mathrm{VI})$ on the column of $\mathrm{TiO}_{2}$ nanotubes was studied. The sample solutions were adjusted to a $\mathrm{pH}$ range of 1.0-8.0 with $\mathrm{HNO}_{3}$ and $\mathrm{NH}_{3}$. $\mathrm{H}_{2} \mathrm{O}$, and then passed through the microcolumn. The retained ions were stripped off the column and measured by ICP-MS, as described in the recommended procedure. The effect of $\mathrm{pH}$ on the recoveries of $\mathrm{Cr}$ (III) and $\mathrm{Cr}(\mathrm{VI})$ are shown in Figure 1. As can be seen, the quantitative recovery (>90\%) was found for $\mathrm{Cr}$ (III) in part of the $\mathrm{pH}$ range 5.0-8.0, whereas that of $\mathrm{Cr}(\mathrm{VI})$ was less than $6.0 \%$. This suggests that it is possible to separate $\mathrm{Cr}$ (III) and $\mathrm{Cr}(\mathrm{VI})$ : $\mathrm{Cr}$ (III) is retained on the column, while $\mathrm{Cr}(\mathrm{VI})$ is not. A pH of 6.0 was selected for this experiment.

TABLE I.

ICP-MS Operating Parameters

$\begin{array}{ll}\text { Plasma Power } & 1300 \mathrm{~W} \\ \text { Plasma Argon Flow Rate } & 14.5 \mathrm{~L} \mathrm{~min}^{-1} \\ \text { Auxiliary Argon Flow Rate } & 0.75 \mathrm{~L} \mathrm{~min}^{-1} \\ \text { Nebulizer Argon Flow Rate } & 0.92 \mathrm{~L} \mathrm{~min}{ }^{-1} \\ \text { Sampler Orifice (nickel) } & 1.1 \mathrm{~mm} \\ \text { Skimmer Orifice (nickel) } & 0.7 \mathrm{~mm} \\ \text { Acquisition Mode } & \text { Peak-jumping } \\ \text { Number of Sweep } & 100 \\ \text { Dwell Time } & 10 \mathrm{~ms} \\ \text { Acquisition Time } & 40 \mathrm{~s} \\ \text { Number of Measurements per Peak } & 3 \text { (number of replicates) } \\ \text { Isotopes } & 52 \mathrm{Cr} \text { and }{ }^{115} \mathrm{In}\end{array}$




\section{Elution of Cr(III)}

As can be seen in Figure 1, the Cr(III) ions were not retained on the $\mathrm{TiO}_{2}$ nanotubes at a higher acidity ( $\mathrm{pH}<1.0)$. Hence, nitric acid was used as the eluent reagent to elute the retained $\mathrm{Cr}$ (III) on the microcolumn packed with $\mathrm{TiO}_{2}$ nanotubes following the above procedure. The effect of eluent concentrations on the recoveries of the analytes was evaluated under the selected experimental conditions. The experimental results show that the elution of $\mathrm{Cr}$ (III) was quantita- tively removed with $2.0 \mathrm{~mL}$ of $1.5 \mathrm{~mol} \mathrm{~L}^{-1} \mathrm{HNO}_{3}$, and good recoveries were obtained (>90\%).

In addition, the effect of eluent volume on the recovery of the analytes was also studied in the $0.5-3.0 \mathrm{~mL}$ range. The results showed that quantitative recoveries for $\mathrm{Cr}$ (III) (>90\%) were obtained when the volume exceeded $1.5 \mathrm{~mL}$. Taking the required sampling volume for ICP-MS into account, $2.0 \mathrm{~mL}$ of $1.5 \mathrm{~mol} \mathrm{~L}^{-1} \mathrm{HNO}_{3}$ was used for all subsequent experiments to ensure complete elution.

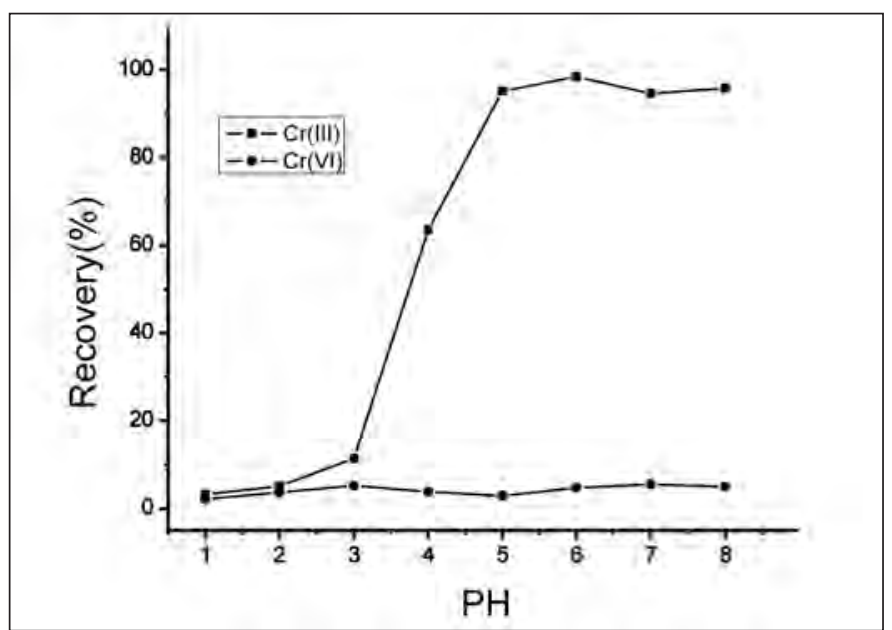

Fig. 1. Effect of pH on recovery of $\mathrm{Cr}(\mathrm{III})$ and $\mathrm{Cr}(\mathrm{VI})$ on $\mathrm{TiO}_{2}$ nanotubes. $\mathrm{Cr}(\mathrm{III})$ and $\mathrm{Cr}(\mathrm{VI})$ : $4.0 \mathrm{ng} \mathrm{mL}^{-1}$ and sample volume: $20 \mathrm{~mL}$.

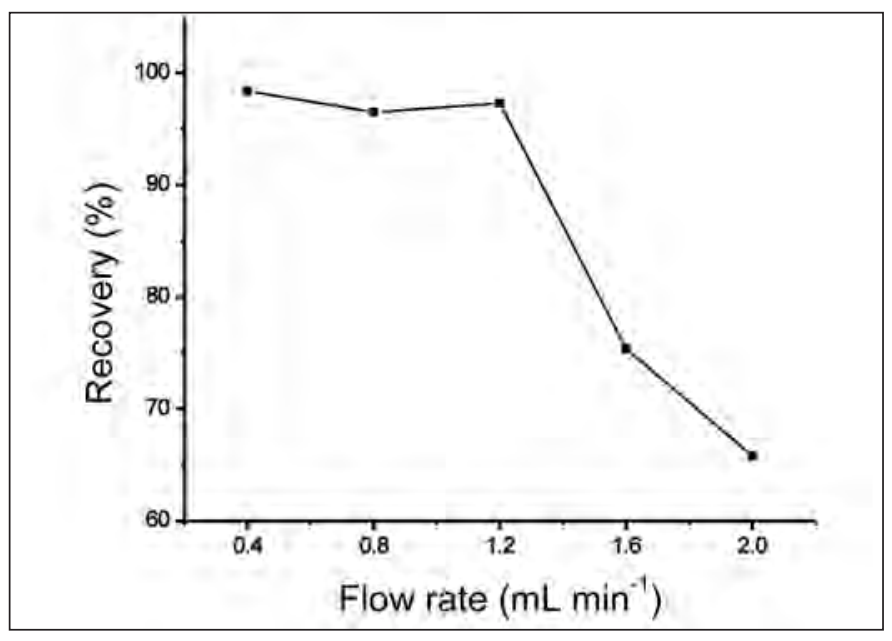

Fig. 2. Effect of flow rate of sample solution on the recovery of Cr(III) on $\mathrm{TiO}_{2}$ nanotubes. pH: 6.O, Cr(III): $4.0 \mathrm{ng} \mathrm{mL}^{-1}$, and sample volume: $20 \mathrm{~mL}$.

\section{Atomic Apectroscopy \\ 1 Vol. 33(5), Sept./Oct. 2012}

\section{Influence of Sample Flow Rate}

The flow rate of the sample solution is also a very important parameter for the quantitative separation of $\mathrm{Cr}$ (III) and $\mathrm{Cr}(\mathrm{VI})$ on $\mathrm{TiO}_{2}$ nanotubes, including the length of the complete analysis. Therefore, the effect of the sample solution flow rate on the retention of $\mathrm{Cr}$ (III) on $\mathrm{TiO}_{2}$ nanotubes was examined under the optimum conditions $(\mathrm{pH}$, eluent, etc.). The flow rate was adjusted in the $0.4-2.0 \mathrm{~mL} \mathrm{~min}{ }^{-1}$ range. It can be seen from Figure 2 that the retention of $\mathrm{Cr}$ (III) was practically unchanged up to $1.2 \mathrm{~mL} \mathrm{~min}^{-1}$, but its retention decreases with higher flow rates due to a decrease in the adsorption kinetics. Accordingly, all subsequent experiments were performed at a

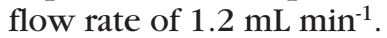

\section{Effect of Sample Solution Volume}

The effects of sample volume on the retention behaviors of $\mathrm{Cr}$ (III) on $\mathrm{TiO}_{2}$ nanotubes was investigated by varying the sample volume containing 10 ng of $\mathrm{Cr}$ (III) from 20 to $200 \mathrm{~mL}$. The results in Figure 3 indicate that when the sample volumes of $\mathrm{Cr}(\mathrm{III})$ were lower than $100 \mathrm{~mL}$, the recoveries of $\mathrm{Cr}(\mathrm{III})$ were all above $90 \%$ and remained constant,

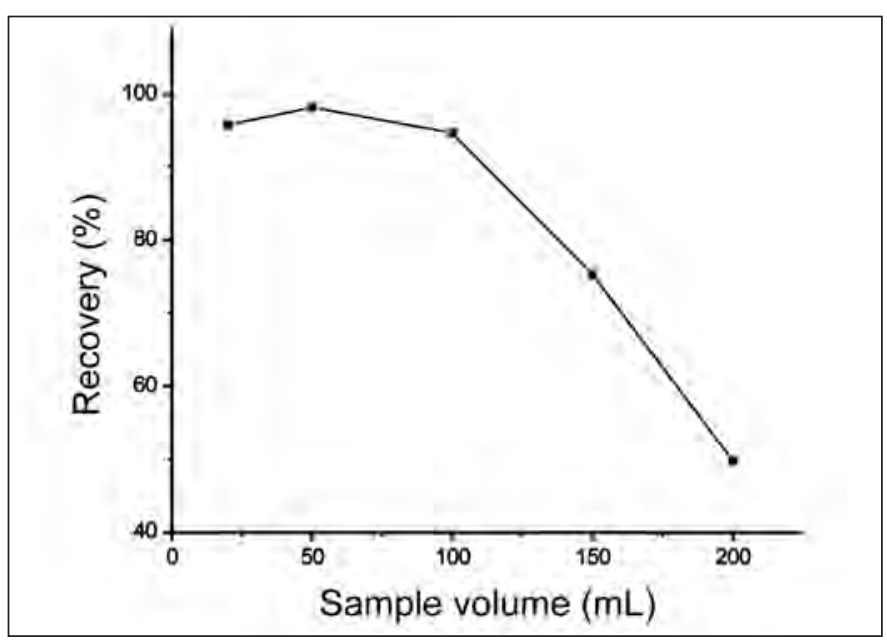

Fig. 3. Effect of sample volume on recovery of $\mathrm{Cr}(\mathrm{III})$ on $\mathrm{TiO}_{2}$ nanotubes. $\mathrm{pH}$ : 6.0; $\mathrm{Cr}(\mathrm{III}): 10 \mathrm{ng}$. 
whereas a decrease of the recovery was observed with the continuous increase of sample volume. As described in the previous section, the analytes were quantitatively recovered using a volume of $2.0 \mathrm{~mL}$ of $1.5 \mathrm{~mol} \mathrm{~L}^{-1} \mathrm{HNO}_{3}$. Thus, an enrichment factor of 50-fold was obtained for the ions studied in this work. Considering the analysis time, a 20-mL sample volume was used for the analysis of real samples.

\section{Adsorption Capacity}

The capacity study used was adapted from that recommended in the literature (23). For this purpose, 20-mL aliquots of a series of concentrations (5.0-30.0 $\mathrm{g} \mathrm{mL}^{-1}$ ) were adjusted to the appropriate $\mathrm{pH}$, and then the preconcentration and separation procedure described above

TABLE II

Tolerance Limits of Coexisting Ions

\begin{tabular}{|c|c|}
\hline $\begin{array}{l}\text { Coexisting } \\
\text { Ion }\end{array}$ & $\begin{array}{c}\text { Concentration } \\
\text { Ratio }^{\mathrm{a}}\end{array}$ \\
\hline $\mathrm{Na}^{+}, \mathrm{K}^{+}$ & $5000^{\mathrm{b}}$ \\
\hline $\mathrm{Ca}^{2+}, \mathrm{Mg}^{2+}$ & $2000^{\mathrm{b}}$ \\
\hline $\mathrm{Fe}^{3+}, \mathrm{Al}^{3+}$ & $500^{\mathrm{b}}$ \\
\hline $\mathrm{PO}_{4}{ }^{3-}, \mathrm{SiO}_{3}{ }^{2-}, \mathrm{SO}_{4}{ }^{2-}$, & $5000^{\mathrm{b}}$ \\
\hline \multicolumn{2}{|c|}{$\begin{array}{l}\text { a Concentration ratio: Foreign ion / } \\
\text { Cr(III). } \\
\text { b Maximum concentrations tested } \\
\text { (each interference ion was added } \\
\text { into the solution, separately). }\end{array}$} \\
\hline
\end{tabular}

was applied. The breakthrough curves were obtained by plotting the metal ion concentrations ( $\mu \mathrm{g} \mathrm{mL}^{-1}$ ) versus the milligrams of metal ions adsorbed on per gram of adsorbent. The adsorption capacity calculated from the breakthrough curve was $8.7 \mathrm{mg} \mathrm{g}^{-1}$ for $\mathrm{Cr}(\mathrm{III})$.

\section{Effect of Interfering Ions}

The effects of common coexisting ions on the adsorption of $\mathrm{Cr}$ (III) on $\mathrm{TiO}_{2}$ nanotubes were investigated. In these experiments, various salts and ions were added individually to a solution containing $4.0 \mathrm{ng} \mathrm{mL}^{-1}$ $\mathrm{Cr}(\mathrm{III})$, and the test procedure described above was applied. The tolerance limit was set as the coexisting ion amount required to cause $\pm 5.0 \%$ error in the determination of the analytes. The results listed in Table II show that the presence of major cations and anions has no obvious influence on the adsorption of Cr(III) under the selected conditions.

\section{Column Reuse}

The stability and potential regeneration of the column packed with $\mathrm{TiO}_{2}$ nanotubes was studied by monitoring the changes in the recoveries of $\mathrm{Cr}$ (III). It was found that the column can be reused after regeneration with $10 \mathrm{~mL}$ of $1.0 \mathrm{~mol} \mathrm{~L}^{-1} \mathrm{HNO}_{3}$ and $20 \mathrm{~mL}$ deionized water, respectively, and is stable up to 40 adsorption-elution cycles without an obvious decrease in the recovery of the analytes.

\section{Detection Limits and Precision}

According to the definition of IUPAC $(3 \sigma)$, the detection limits of this method for $\mathrm{Cr}$ (III), calculated from three times the standard deviation of the blank signal, was $0.023 \mathrm{ng} \mathrm{mL}^{-1}$ with the relative standard deviation of $3.8 \%(n=9$, $\mathrm{c}=0.5 \mathrm{ng} \mathrm{mL}^{-1}$ ).

\section{Analysis Application}

The feasibility of the determination for $\mathrm{Cr}(\mathrm{III})$ and $\mathrm{Cr}(\mathrm{VI})$ on $\mathrm{TiO}_{2}$ nanotubes was explored in water samples including reference material (obtained from P.R. China), groundwater from the market, and wastewater from an industrial site in Wuhan City. The proposed preconcentration and separation technique was applied to the analysis of Cr species by the internal standard method (using In as the internal standard element). The reliability was checked by spiking the experiments. The results listed in Table III indicate that the recoveries are reasonable for trace analysis, in a range of $94.2-102 \%$.

\section{CONCLUSION}

In this work, the adsorption behavior of $\mathrm{Cr}$ (III) and $\mathrm{Cr}(\mathrm{VI})$ on $\mathrm{TiO}^{2}$ nanotubes has been investigated systematically. The experimental results indicate that $\mathrm{Cr}(\mathrm{III})$

Table III

Analytical Results and Recoveries of Cr(III) and Cr(VI) in Water Samples

\begin{tabular}{|c|c|c|c|c|c|c|c|}
\hline \multirow[t]{2}{*}{ Sample } & \multicolumn{2}{|c|}{ Added (ng mL $\left.{ }^{-1}\right)$} & \multicolumn{3}{|c|}{ Found $^{\mathrm{a}}\left(\right.$ ng $\left.\mathrm{mL}^{-1}\right)$} & \multicolumn{2}{|c|}{ Recovery (\%) } \\
\hline & $\mathrm{Cr}(\mathrm{III})$ & $\mathrm{Cr}(\mathrm{VI})$ & $\mathrm{Cr}(\mathrm{III})$ & $\mathrm{Cr}(\mathrm{VI})^{\mathrm{b}}$ & Total & $\mathrm{Cr}(\mathrm{III})$ & $\mathrm{Cr}(\mathrm{VI})$ \\
\hline \multirow[t]{2}{*}{ GSBZ 5009-88 } & - & - & & - & $668 \pm 45$ & - & - \\
\hline & 500 & - & & - & $1150 \pm 72$ & 96.4 & - \\
\hline \multirow[t]{2}{*}{ Ground Water } & 0 & 0 & $0.98 \pm 0.06$ & $0.52 \pm 0.04$ & $1.50 \pm 0.11$ & - & - \\
\hline & 1.0 & 1.0 & $1.93 \pm 0.13$ & $1.54 \pm 0.11$ & $3.47 \pm 0.29$ & 95.0 & 102 \\
\hline \multirow[t]{2}{*}{ Wastewater } & 0 & 0 & $6.72 \pm 0.56$ & $2.75 \pm 0.19$ & $9.47 \pm 0.42$ & - & - \\
\hline & 5.0 & 5.0 & $11.6 \pm 0.57$ & $7.46 \pm 0.37$ & $19.06 \pm 1.23$ & 97.6 & 94.2 \\
\hline
\end{tabular}

\footnotetext{
${ }^{\mathrm{a}}$ Mean value \pm standard deviation, $\mathrm{n}=5$.

${ }^{\mathrm{b}}$ Calculated value.

${ }^{\mathrm{c}}$ National reference material (China): the certified value of $\mathrm{Cr}$ concentration is $640 \pm 36 \mathrm{ng} \mathrm{mL}^{-1}$.
} 
was almost quantitatively retained in the $\mathrm{pH}$ range of 5.0-8.0, while $\mathrm{Cr}(\mathrm{VI})$ remained in the solution. The $\mathrm{Cr}$ (III) retained on $\mathrm{TiO} 2$ nanotubes can be easily desorbed, and no carryover is observed in the next analysis. An enrichment factor of 50-fold was achieved. Based on the high adsorption selectivity of the $\mathrm{TiO} 2$ nanotubes for $\mathrm{Cr}$ (III) and Cr(VI), a simple, rapid, and reliable method was developed for the preconcentration, separation, and determination of chromium species in environmental water samples by the microcolumn packed with $\mathrm{TiO} 2$ nanotubes coupled with ICP-MS.

\section{ACKNOWLEDGMENTS}

Financial support from the Nature Science Foundation and the Education Department Foundation of Hubei Province in China is gratefully acknowledged.

Received July 1, 2012.

\section{REFERENCES}

1. V. Comez and M. P. Callao, Trends Anal. Chem. 25(10), 1006 (2006).

2. P. Pazos-Capeáns, M. C. BarcielaAlons, A. Bermejo-Barrera, P. Bermejo-Barrera, A. Fisher, and S. J. Hill, At. Spectrosc. 27(4), 107 (2006).

3. A. Aparna, M. Sumithra, G. Venkateswarlu, and A. C. Sahayam, At. Spectrosc. 27(4), 123 (2006).

4. M. S. El-Shahawi, S. S. M. Hassan, A. M. Othman, and M. A. El-Sonbati, Microchem. J. 89(1), 13 (2008).

5. B. Áron, K. Roland, and P. József, Microchem. J. 85(1), 103 (2007).

6. K. Hiiro, T. Ouwa, M. Takaoka, and T.Tanaka, Bunseki Kagaku 25, 122 (1976).

7. R. E. Cranston and J. W. Murray, Anal. Chim. Acta 99, 275 (1978).

8. S. Hirata, K. Honda, and T. Kumamaru, Anal. Chim. Acta 221, 65 (1989).

9. V. Emilia, H. Konstantin, S. Teodor, and D. Christo, Analyst 125, 693 (2000).

10. S. Motomizu, K. Jitmanee, and M. Oshima, Anal. Chim. Acta 499, 149 (2003).

11. L. S. Krull, D. Bushee, R. N. Savage, R. G. Schleicher, and S. B. Smith, Anal. Lett. 15, 267 (1982).

12. M. Boussemart, C. M. G. van den Berg, and M. Ghaddaf, Anal. Chim. Acta 262, 103 (1992).

13. C. J. Jimmy, W. Xiujuan, and C. Zuling, Anal. Chim. Acta 436, 59 (2001)

14. W. Yiwei, J. Yinyan, H. Deyan, W. Fang, and Z. Junxia, Microchim. Acta 159(3-4), 333 (2007).

15. S. Chen, M. Xiao, D. Lu, and Z. Wang, Spectrochim. Acta Part B 62, 1216 (2007).

16. R. Yinzhe, F. Zhefeng, and W. Jianying, Microchim. Acta 158 (3-4), 227(2007).

17. W. Hong, W. Hongyu, H. Baoping, D. Baixiang, L. Jusheng, and T. Jiuying, Microchim. Acta 166(1-2), 41(2009).

\section{Atomic Apectroscopy \\ 1 Vol. 33(5), Sept./Oct. 2012}

18. Z. Li, S. Chen, D. Lu, and X. Cheng, At. Spectrosc. 30(6), 217 (2009).

19. Y. Cui, X. Chang, Y. Zhai, X. Zhu, H. Zheng, and N. Lian, Microchem J 83: 35. (2006).

20. Y. Cai, G. Jiang, J. Liu, Q. Zhou, Anal. Chem. 75, 2517 (2003).

21. Q. Zhou, X. Zhao, and J. Xiao, Talanta 77, 1774 (2009).

22. Q. Zhou, X. Zhao, and J. Xiao, At. Spectrosc, 29, 145 (2008).

23. A. Maqieira, H. A. M. Elmahadi, and R. Puchades, Anal. Chem. 66, 3632 (1994). 